\title{
Demosthenes, De Corona §§ 169-170 in P.CtYBR inv. 4671
}

\author{
Mark de Kreij*
}

\begin{abstract}
A scrap of papyrus from the Beinecke library, dating to the late first century $\mathrm{BCE}$ or early first century CE, has yielded a passage from Demosthenes' De Corona. The text is good, and in one place offers further support for Demosthenes' avoidance of hiatus.
\end{abstract}

Keywords: Demosthenes, De Corona, hiatus, Yale

DOI 10.1515/apf-2015-0003

Yale papyrus CtYBR 4671 was purchased in 1997 from Galerie Nefer, Zurich (provenance unknown). I would like to thank the Yale Papyrus Collection, Beinecke Rare Book and Manuscript Library, for providing the digital images, and Dr. Dobbin-Bennett for her efficient assistance. The fragment measuring 6.3 by $11.3 \mathrm{~cm}$ contains 16 lines of a column, written along the fibres (the back is blank), which I have identified as Demosthenes' De Corona. Line length fluctuates between 16 (1. 7) and 21 (1. 9) letters; at its most narrow, intercolumnium is $1.55 \mathrm{~cm}$. There are indeterminate traces of the preceding column: 1, 2, 5 ( ]c ) ), 6, 9, 10 ( ] $\alpha \lambda$ ) $11,12$, and 16 ( $] \varepsilon$ ). The bottom margin appears to be preserved, no top margin remains. There is one apparent sign of punctuation, a high stop before kai in line 7 (which would coincide with the start of $\S 170$ ), but no accents. Elision is effected, but it is unclear if it was marked (lines 8,15 ).

The hand is a slowly written upright, but not very consistent in letter forms and spacing, with a few ligatures ( $\alpha 11.4,11$ and $\varepsilon 11.14)$. Besides $\mathrm{r}$, $\beta$, and (to a lesser extent) $\rho$, the left upright of $\eta$ also extends above the line, and there is no real sense of bilinearity. There is some contrastiveness in letter size, but omicron, omega, and sigma are only slightly smaller than the other letters, and they do not hang from the top of the line. $\eta$ is written

\footnotetext{
* Corresponding author: Mark de Kreij, 27 Bridge St., Oxford OX2 0BA, United Kingdom, $<$ de_Kreij@uni-heidelberg.de>
} 
with a loop in the upper left and a curved right-hand side, $\kappa$ has a little hook to the left at the top of the upright; $\pi$ has uprights that curve outward at the bottom; $\alpha$ vacillates between round and angular (e.g. 1. 11). Especially remarkable is the strong slant of the a, parallelled in the 'climbing' $\mu$ and $\nu$ which seem tilted towards the left. The letters at the beginning of the line are typically slightly enlarged (cf. Turner, GMAW p. 7).

It looks like a skilled documentary scribe aiming for a book hand. We might compare it to the "formal documentary script" (Cavallo/Maehler, $H B$ p. 16) sometimes used to copy literary texts in the second century $\mathrm{BCE}$. The relative lack of ligatures in our papyrus can be explained from the scribe's attempt to write slowly and carefully (cf. P.Dion. 25, 104 BCE $=$ Cavallo/Maehler, $H B$ no. 53). The hand shows a general similarity to the documentary hands of P.Oxy. II 282 (Roberts, GLH no. 10b, 30-35 CE) and P.Oxy. II 246 (Roberts, GLH no. 10c, $60 \mathrm{CE}$ ), but some letter forms (especially $\pi, \eta$, and round $\alpha$ ) are better parallelled in P.Oxy. XII 1453 (Roberts, GLH no. 8b, 30-29 BCE). A date in the late first century BCE or early first century CE therefore seems most likely.

I have collated the papyrus with Dilts 2002 Demosthenis Orationes I and Fuhr 1914 Demosthenis Orationes I, and the sigla in the notes are taken from the same editions. The papyrus gives a good text: one mistake is corrected by what appears to be the same hand (1.12), and the only

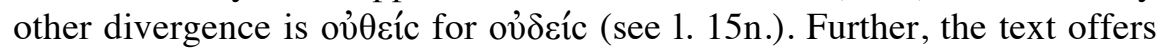
one variant that looks to be superior to the reading of the mss. (see 1. 8n.).

This papyrus makes a total of twenty-seven papyri of De Corona, based on the $\mathrm{MP}^{3}$. It may be worth noting that this is the fourth papyrus containing (part of) $\S 169$ (along with P.Ryl. I 57, P.Paramone 2, and P.Oxy. XI 1377). Comparison with the other extant papyri of De Corona reveals three things: (1) None of the published papyri are a match for the hand, nor are two unpublished papyri in the Oxyrhynchus Collection (MP $^{3}$ 282.01: P.Oxy. inv. 34 4B.77/D(2-3)a, 34 4B.77/D(4-6)c,d and 282.02: P.Oxy. inv. C $22922-7) ;{ }^{1}$ (2) the two papyri that give part of the same passage as our papyrus do not have the same line division (P.Ryl. I 57 and P.Paramone 2); (3) a number of papyri containing other passages from $D e$ Corona have similar line lengths. ${ }^{2}$ The Yale papyrus may be part of a

\footnotetext{
${ }^{1}$ A comparison with the other early Demosthenes papyri in $\mathrm{MP}^{3}$ has yielded no matches either.

${ }^{2}$ P.Köln VIII 334, P.Mil. Vogl. I 12, P.Oxy. III 462, and P.Oxy. XI 1377.
} 
similar editorial tradition as these fragments, but the question of line-byline copying is still open (see Johnson, Bookrolls and Scribes, pp. 48-49).

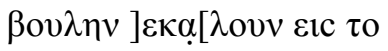

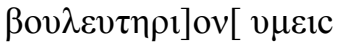

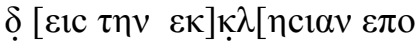

$\rho[\varepsilon v \varepsilon c \theta \varepsilon] \kappa \propto \iota \iota \pi \rho[1 v \varepsilon \kappa \varepsilon เ v \eta v$

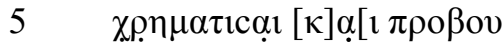

$\lambda \varepsilon v c \alpha \iota \pi[\alpha c]$ o $\delta \eta[\mu \mathrm{oc} \alpha v \omega$

$\kappa \alpha \theta \eta \underline{\tau}[\mathrm{o}] \cdot \kappa \alpha[1 \mu \varepsilon \tau \alpha \tau \alpha v$

$\theta \omega \mathrm{c} \eta \lambda \theta \varepsilon \varphi \eta \eta[\beta \mathrm{ov} \lambda \eta \kappa \alpha 1$

$\alpha \pi \eta \gamma \gamma \varepsilon\llcorner\lambda \alpha \underline{\mathrm{o}} \mathrm{o}[\mathrm{\imath} \pi \rho v \tau \alpha \nu \varepsilon ı \mathrm{c}$

$10 \tau \alpha \pi \rho \operatorname{\alpha \rho } \gamma \gamma \varepsilon \lambda[\mu \varepsilon v \varepsilon$

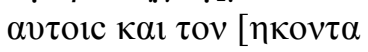

$\pi \alpha \rho \eta \gamma \alpha \gamma \circ v^{~} \kappa \alpha{ }^{\prime} \kappa \varepsilon ![$ [

$\eta \rho \omega \tau \alpha \mu \varepsilon v$ о $\kappa[\eta \rho v \xi \tau i c ~$

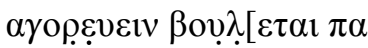

15

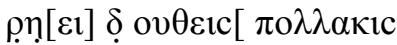

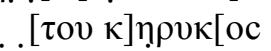

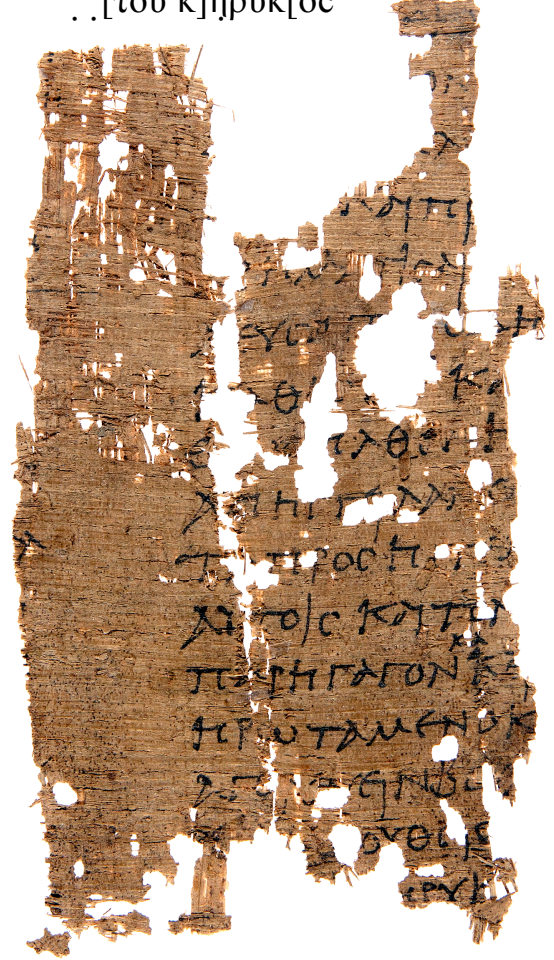


$7 \kappa \alpha \theta \eta \tau[0]$ : The majority of manuscripts reads $\kappa \alpha \theta \eta \tau$, excepting only $\mathrm{A}$ and $\mathrm{Y}$, which read $\kappa \alpha \theta \eta \mathrm{c} \tau$. Although the papyrus is damaged and the traces are faint, it is reasonably certain that the papyrus has the prevalent reading.

After $\kappa \alpha \theta \eta \tau[0]$ there is a trace of ink high on the line, that cannot be part of line 6, nor of any likely letter after [o]; it appears to be a high stop. The lacuna seems large for only an omicron, which suggests that the first hand left a wider space; the punctuation is in the same ink.

8 The $\theta$ is certain (and certainly not $\varepsilon$ ), and what precedes the sigma cannot be iota, but does match the upper right curve of the omega. Both facts support the reading of $\dot{\omega} c$ over $\varepsilon i c$, as in the majority of manuscripts (only $\mathrm{F}$ and $\mathrm{Y}$ have $\varepsilon \dot{i} \hat{\imath} \lambda \theta \varepsilon v$ ). The reading $\tau \alpha \hat{v} \theta^{\prime} \dot{\omega} \mathrm{c}$ over $\tau \alpha \hat{\tau} \tau \alpha \dot{\omega} \mathrm{c}$ (mss.) contributes to a long-standing discussion about hiatus in Demosthenes. In his most recent edition of the orations (Demosthenis Orationes I-IV, 2002-2009), Dilts allows hiatus if it is supported by "two primary manuscripts," and avoids it if the manuscripts are at variance (Dilts 2002, pp. xvii-xviii). His edition gives $\tau \alpha \hat{v} \tau \alpha \dot{\omega} \mathrm{c}$ five times in a running sentence (including here) versus fifteen times $\tau \alpha \hat{v} \theta^{\prime} \dot{\omega} c{ }^{3}$ Here, the syn-

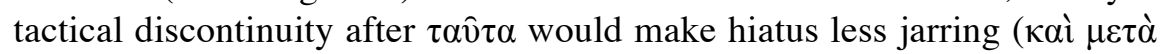
$\tau \alpha \hat{\tau} \tau \alpha, \dot{\omega} c \kappa \tau \lambda$.), but elsewhere the manuscripts elide in a similar situation. ${ }^{4}$ The reading of the papyrus supports the tendency of the manuscripts elsewhere, which suggests that $\tau \alpha \hat{v} \theta^{\prime} \dot{\omega} \mathrm{c}$ is the better reading in this locus too.

10-11 Considering the space left at the end of line 10 , the $\varepsilon$ of $\dot{\varepsilon} \alpha v \tau$ oic was probably written as in the majority of manuscripts, rather than the

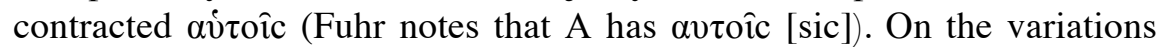
$\dot{\varepsilon} \alpha v$-/ $\alpha \dot{v}$ - in epigraphy see Threatte, Gram. II, 313-325 and for the manuscript tradition see Mayser, Gram. I.2, 65 and Gignac, Gram. II, 170-171.

The space would even allow $-\mu \varepsilon v \alpha \varepsilon$ (as most mss.), but elision seems more likely, considering lines 8 and 15. In either case, line 10 must have been markedly shorter than 9 . One may assume that in line 10 letters were more widely spaced or a space filler was used at line-end to keep a roughly straight right-hand margin.

\footnotetext{
${ }^{3}$ In two further instances, there is a strong syntactic discontinuity between $\tau \alpha \hat{\tau} \tau \alpha$ and $\dot{\omega} \mathrm{c}$, represented by a period in modern editions: Contra Zenothenim $\S 12.1$ and Pro Phormione $\S 22.10$.

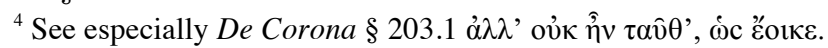


$12 \kappa \alpha$ added above the line just over the $\nu$ of $\pi \alpha \rho \eta \gamma \alpha \gamma o v$ and the $\kappa$ of кeivoc, in the same hand.

15 ov $\theta \varepsilon ı$ : This alternative spelling is the prevalent form in papyri and inscriptions of the Ptolemaic period, which is corroborated by the quote of

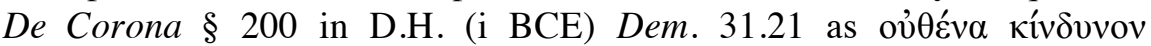

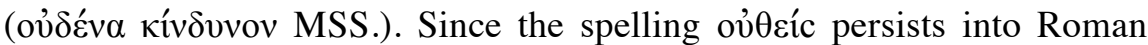
times, however, it cannot itself provide a terminus ante quem. The spelling variant reflects the "assimilation of /d/ before a rough breathing (the

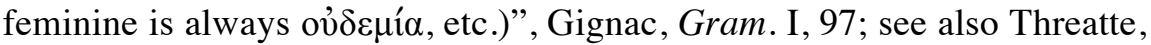
Gram. I, 472-47, Mayser, Gram. I.1, 149, and Schwyzer, GG I p. $408 \delta$ for further discussions of the issue. In a recent edition of the Isocrates papyri, the editor notes that overíc, quite common in a Ptolemaic papyrus of the Plataicus (P.Yale 103v, iii BCE), never occurs in the manuscripts. ${ }^{5}$

16 ... the papyrus is almost completely abraded, but the preceding line and the extant letters later in this line make it likely that $\delta \dot{\varepsilon}$ stood here.

\footnotetext{
${ }^{5}$ F. Adorno et al. (eds) 2008. Corpus dei papiri filosofici greci e latini, Parte I.2**, Galenus-Isocrates (Firenze) 886.
} 